\title{
Is a Rational Politics of Disaster Possible? Making Useful Decisions for Others in an Experimental Disaster Game
}

\author{
Talbot M. Andrews ${ }^{1} \mathbb{D} \cdot$ Andrew W. Delton $^{2} \mathbb{D} \cdot$ Reuben Kline $^{3} \mathbb{D}$
}

Accepted: 8 March 2021 / Published online: 19 March 2021

(c) The Author(s), under exclusive licence to Springer Science+Business Media, LLC, part of Springer Nature 2021

\begin{abstract}
Disaster responses are political. But can citizens make useful disaster decisions? Potential obstacles are that such decisions are complex, involve public goods, and often affect other people. Theories of political decision-making disagree on whether these problems can be overcome. We used experimental economic games that simulate disaster to test whether people are willing and able to prevent disasters for others. Groups of players face a complex task in which options that might help vary in their riskiness. Importantly, although all options are reasonable, which option is most useful depends on the experimental condition. We find that players will pay to help, can identify which option is most useful across experimental conditions, and will pay to learn how best to help. Thus, players were able to make useful and costly decisions to prevent others from experiencing disaster. This suggests that, in at least some situations, citizens may be able to make good disaster decisions.
\end{abstract}

Keywords Disaster $\cdot$ Public goods $\cdot$ Social preferences $\cdot$ Experimental political science

Preventing and mitigating disasters depends on choices made by citizens as individuals and through politics. Consider wearing face masks during the pandemic of the

Talbot M. Andrews

talbot.andrews@gmail.com

$\triangle$ Andrew W. Delton

andrew.delton@stonybrook.edu

$\bowtie$ Reuben Kline

reuben.kline@stonybrook.edu

1 Department of Political Science, University of Connecticut, Storrs, CT, USA

2 Department of Political Science, College of Business, Center for Behavioral Political Economy, Stony Brook University, Stony Brook, NY, USA

3 Department of Political Science, Center for Behavioral Political Economy, Stony Brook University, Stony Brook, NY, USA 
novel coronavirus causing COVID-19. First, it's a complex question of when, where, and by whom masks are best worn (Sunjaya \& Jenkins, 2020). Second, standard masks worn by the public are generally thought to mostly protect others (SousaPinto et al., 2020). Third, mask wearing is a public good. If one individual abstains from mask wearing (for instance, to avoid the discomfort), the collective impacts are probably negligible; yet if everyone abstains, the virus will spread more easily (Zhang et al., 2020) - in a public good, individual rationality creates collective inefficiency.

This trio of complexity, affecting others, and being a public good is why, in part, disasters require politics to coordinate effective prevention efforts. But can citizens collectively make good disaster decisions? We complement existing observational work on disaster politics by using economic game experiments to study this question. Economic games allow us to simulate disaster prevention in a way that is fully controlled, transparent, and involves real monetary stakes. In our games, we test whether players can contribute effectively as a group to prevent a complex disaster that only affects others. If they fail to prevent the disaster, the other group loses all of their earnings. Importantly, the best way to help is not obvious, but requires choosing among multiple options, all of which are reasonable but only one of which is best. Will citizens collectively identify the best solution and be willing to pay to implement it?

\section{The Political Nature of Disasters}

A variety of disasters are characterized by complexity, public goods, or making decisions that affect others. Consider greenhouse gas emissions and climate change. One complexity is determining which approaches will sufficiently reduce emissions while minimizing negative effects on the global economy (e.g., perhaps some mixture of carbon pricing, carbon caps, and technological approaches) (IPCC,2014). Another complexity is how to divide current responsibility between historically high and low emitters. Climate change is also a global social dilemma because any given country need do nothing if most others make significant sacrifices. Finally, the people making the decisions are not always those who will be most affected; rich countries and current generations will determine responses to climate change, but poor countries and future generations will be most affected.

Or consider disasters like hurricanes, wildfires, and coastal flooding, which open difficult questions about how to prepare and evacuate. Sometimes, preparing helps a person reduce their own risk of injury (FEMA, 2004; Paton, 2003). But sometimes preparing is a public good, providing benefits for others. When hurricanes approach the coast, at-risk communities are asked to evacuate, while others are encouraged to shelter in place. But if low-risk people "shadow" evacuate anyway, they increase traffic, slow down evacuation, and raise everyone's risk (Stein et al., 2014). Shadow evacuations still occur because preparing to shelter in place is so complex: What supplies and food will you need? What will you do if the power goes out? People's concerns about their own risks often drive preparedness and evacuation behavior (Drabek, 1983; Lindell \& Perry, 2012; Mileti \& Sorensen, 1987; Van Der Pligt, 
1998). But this leaves open the question of whether people are also willing and able to make these decisions to help others.

\section{How Will People Decide for Others?}

Theories diverge on whether citizens will be motivated and able to make effective choices to help others. At least since the classic work of Downs (1957), some theories have assumed that people are self-interested and, for instance, will prefer policies give them the most money or cost them least in taxes. It does not bode well for disaster politics if most citizens are self-interested. First, when a disaster affects others, unaffected citizens should not bother to gather or think about relevant information on how to help, nor sacrifice to put any decision into action. Second, complexity will exacerbate this problem; a self-interested citizen should be even less willing to pay the cognitive costs to unravel a complex problem. Third, even if a citizen has some personal stake in disaster prevention, if the disaster is a public good, it could still be individually reasonable for a self-interested citizen to do nothing. Selfinterested citizens are unlikely to do a good job making costly and complex disaster decisions on behalf of others.

Other theories assume that for many people political activity is not instrumentally selfish, but motivated by social preferences or sociotropic goals (Fowler \& Kam, 2007; Hamlin \& Jennings, 2011; Kinder \& Kiewiet, 1981). For instance, the mere act of giving might create a "warm glow" (Andreoni, 1995). Or, people might be motivated to be seen by themselves or others as making the ethical choice (Feddersen et al., 2009). Another possibility-which is our focus-is that people are motivated to be instrumentally beneficial, meaning they care whether their choices actually help others (Dawes et al., 2015; Del Ponte et al., 2021; Edlin et al., 2007; Fowler \& Kam, 2007). If citizens care about how political and economic decisions affect others, their calculus changes (Bolsen et al., 2014; Edlin et al., 2007). Studies find that social preferences predict voting (Fowler, 2006), political activity (Dawes et al., 2015), helping or spiting political parties (Del Ponte et al., 2021), and supporting social welfare programs (Gilens \& Thal, 2018). Further, people engage in more disaster preparedness when they are concerned about their community, not just themselves (Kim \& Kang, 2010). This view predicts that people will be willing to sacrifice for others and will do so in a way that actually helps.

Theories of self-interest and of instrumental social preferences assume that people are broadly rational in considering their own interests or the interests of others. However, other theories suggest that, at least in politics, citizens may not be rational. They may be too blinded by a "partisan screen," they may lack coherent political beliefs, or they may rely on inadequate heuristics to make decisions (Campbell et al., 1980; Converse, 1964; Kuklinski \& Quirk, 2000). Citizens also are often uninformed about politics (Delli Carpini \& Keeter, 1993). Many of these pathologies extend to the domain of disaster response: Individuals struggle to reason about how best to prepare themselves for disasters (Lindell \& Perry, 2012), their responses and attributions of blame can be overly influenced by partisan considerations (Chen, 2013; Heersink et al., 2020; Malhotra \& Kuo, 2008), and they may 
blame incumbents despite a broad and fair distribution of disaster aid (Heersink et al., 2017). In this view, even if citizens are willing to help, their decisions are likely random or ineffective.

Our games were designed to discriminate between these theories. Thus, we did not use voting games. Though they have proven useful in many applications, voting games cannot distinguish between self-interest and instrumental social preferences. Because a vote is unlikely to be decisive in a large electorate, in expectation there is no benefit to voting, so self-interested people are unlikely to vote (Downs, 1957). This is true even when the potential voter has personal benefits at stake in the election. Less obvious is that this same problem affects instrumental social preferences in the context of voting (Feddersen et al., 2009). It's true that social preferences can sustain more voting than can self-interest (Edlin et al., 2007). But ultimately it is still a cost-benefit calculation: The costs of going to the polls or becoming informed might still outweigh the benefits to self and others once those benefits are discounted by the low probability one's vote matters. Therefore, because the context of voting introduces this general problem of democratic decision making, not specific to disasters, we chose not to use a voting game. Instead, in our games, each person can realistically influence the outcome with their choices. This way we can study how people think about solving disasters collectively and, simultaneously, we can arbitrate between different theories about political decision-making.

\section{Using Economic Games to Study Disaster Prevention}

Many approaches are useful for studying disaster politics, including public opinion research, survey experiments, and laboratory studies (e.g., Bernauer \& McGrath, 2016; Myers et al., 2013). One promising approach, which we use here, uses economic games to simulate disasters (e.g., Barrett \& Dannenberg, 2012; Bynum et al., 2016; Dannenberg et al., 2015; Del Ponte et al., 2017; Dreber \& Nowak, 2008; Jacquet et al., 2013; Milinski et al., 2008, 2016; Tavoni et al., 2011). Economic games allow researchers to create carefully controlled simulations of important political and economic situations (Morton \& Williams, 2010; Wilson, 2011; Woon, 2012). Players are given clear rules about how they and others will earn real money. Although games are stylized, they have virtues that make them a valuable tool. Like real-world situations, games involve material incentives; unlike real-world situations, we can fully understand and control these incentives. Like survey experiments, games allow random assignment and thus generate strong causal inferences; unlike survey experiments, the clear material incentives allow us to compare the behavior of players to game theory predictions.

Games also have drawbacks. Game stakes cannot of course match the stakes of real disasters. Nonetheless, games are played similarly whether played for typical lab stakes ( \$1-\$20) or amounts worth about a month's wage (Henrich et al., 2005). Also, because games are abstract, they may not activate partisanship or ideology as would a real-world problem. In some ways, this is a benefit. Real political decisions result from many interacting people, groups, laws, and institutions. Games allow us 
to isolate a specific mechanism and study it carefully. Still, to help our players see our games as connected to the real world, we explicitly described them as simulating climate disaster. How games are framed affects players' behavior (e.g., Delton et al., 2020; DeScioli \& Krishna, 2013). By describing ours as disaster, we helped players' choices map onto relevant real-world decisions.

Helping others avoid disaster involves generosity. Research on social preferences amply confirms that many people are generous, even with anonymous others (e.g., Andreoni, 1995; Charness \& Rabin, 2002). The most common method used to study social preferences is the dictator game. In typical dictator games, from a pair of two anonymous players, one is randomly selected to play as the "dictator." The dictator unilaterally decides how to divide a stake of real money (e.g., \$10) between herself and her partner. Dictators often give substantial percentages of the stake, including splitting it evenly (e.g., Camerer, 2011). Although useful, the dictator game conflates many possible social preferences. Dictators might give because it feels good to give or to be seen doing good. Even if dictators are instrumentally concerned with their partner's welfare, the game doesn't discriminate between motives. Dictators might give because they dislike inequality or simply to improve the partner's payoff. Notice also how straightforward the game is: The decision is unilateral; any dollar given away is definitely a dollar received. Although some past work has studied how groups behave in the dictator game and other simple games (with mixed results on whether groups are more or less generous than individuals: Bornstein \& Yaniv, 1998; Cason \& Mui, 1997), this doesn't test how groups behave in complex decision environments.

\section{The Disaster Game}

Thus, although research with the dictator game and similar games confirms that people will be generous, it does not allow us to answer our question: Can people collectively make good disaster decisions when the problem is complex, affects others, and is a public good? To do this, we draw on and modify the disaster game (Andrews et al., 2018; Barrett \& Dannenberg, 2012, 2014; Dannenberg et al., 2015; Del Ponte et al., 2017; Milinski et al., 2008, 2016).

A typical disaster game might proceed as follows. Four players in a group each start with a personal pot of real money denominated as 100 tokens ( 1 token $=\$ 0.20$; $\$ 20$ total). (Details vary; we draw from our studies.) When the game starts there is a 90\% chance disaster wipes out everyone's money. But the group can prevent disaster if they collectively contribute enough to a shared disaster "threshold" worth 120 tokens (an average of 30 tokens per player). Figure 1 illustrates this. But players can also defect, which makes the game a type of public good. ${ }^{1}$ A player can keep their

\footnotetext{
1 The disaster game differs from the standard (linear) public goods game. Standard public goods games involve a group creating a shared benefit; the disaster game involves preventing a shared loss, which is better for simulating disasters. Also, the disaster game is a threshold game: There is a sharp point at which the public good is attained. In game theory terms, this makes the disaster game a coordination game, not a pure social dilemma. In turn, this makes cooperation more likely than in standard public goods games (Jordan et al., 2017).
} 


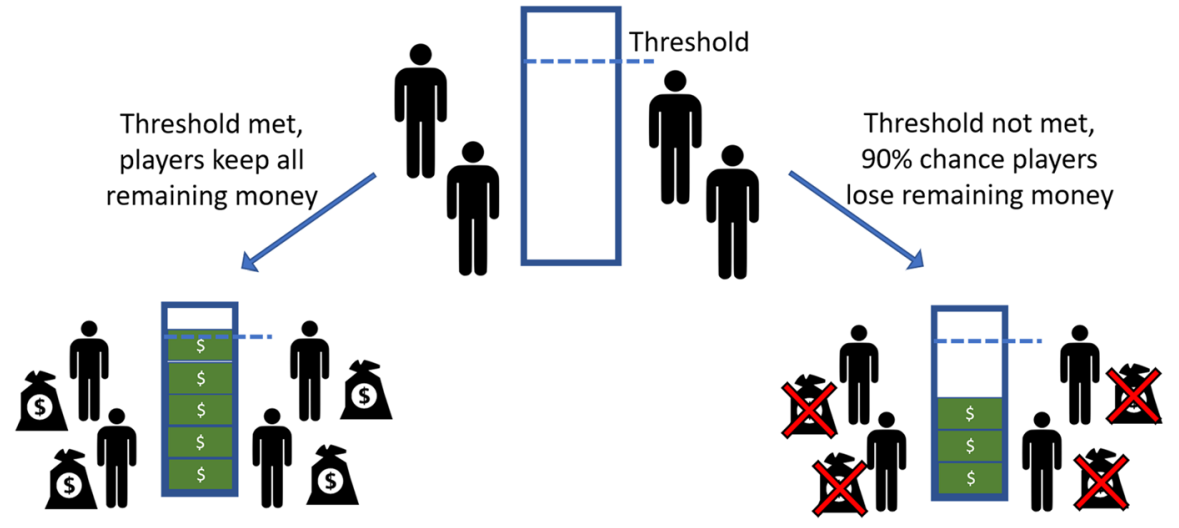

Fig. 1 The consequences of meeting or failing to meet the threshold for others

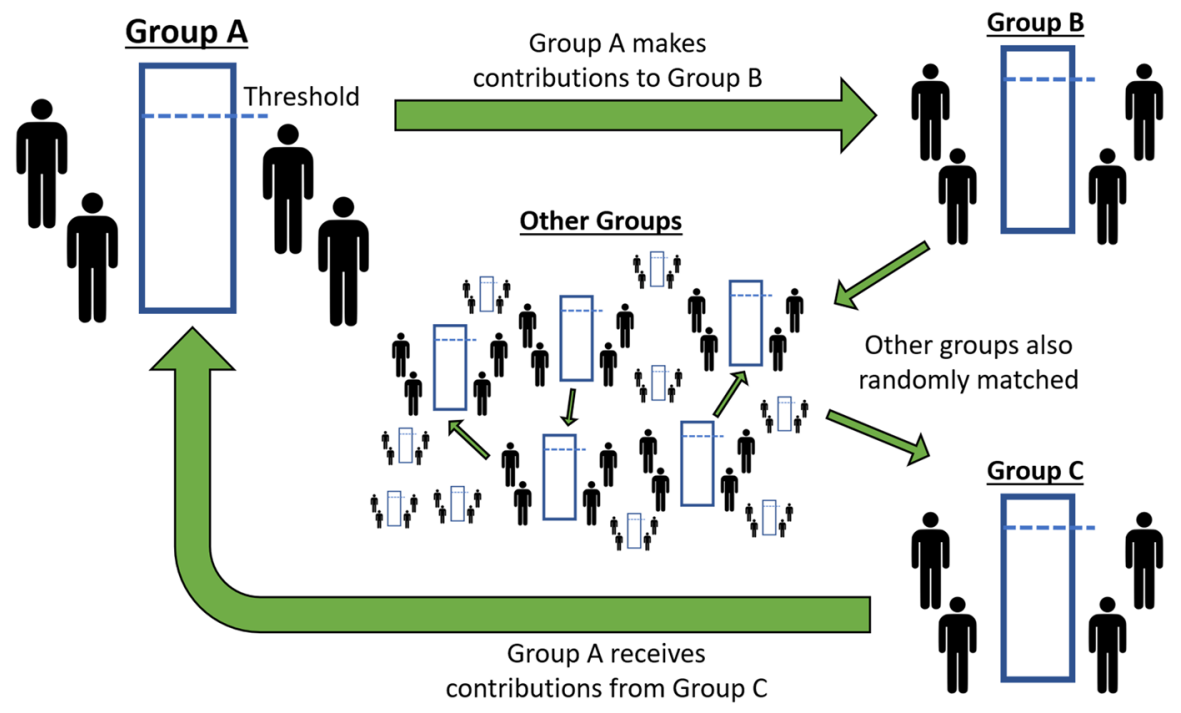

Fig. 2 How groups are matched to make decisions for one another

money and hope the others contribute enough. Nonetheless, people are good at solving the disaster game (see above cites).

We are interested in people preventing disaster for others. Thus, we modify the game such that a group's contributions only help another, anonymous, randomly determined group, which we call a "beneficiary group." A group's contributions, while costly, cannot be used to help themselves at all. Importantly, groups are not reciprocally helping each other. See Fig. 2.

We also make contributing complex by modifying the game in three ways (following Andrews et al., 2018). First, players make a binary contribution of either 0 tokens or 20 tokens (i.e., a full $20 \%$ of their stake). Second, between groups we vary 


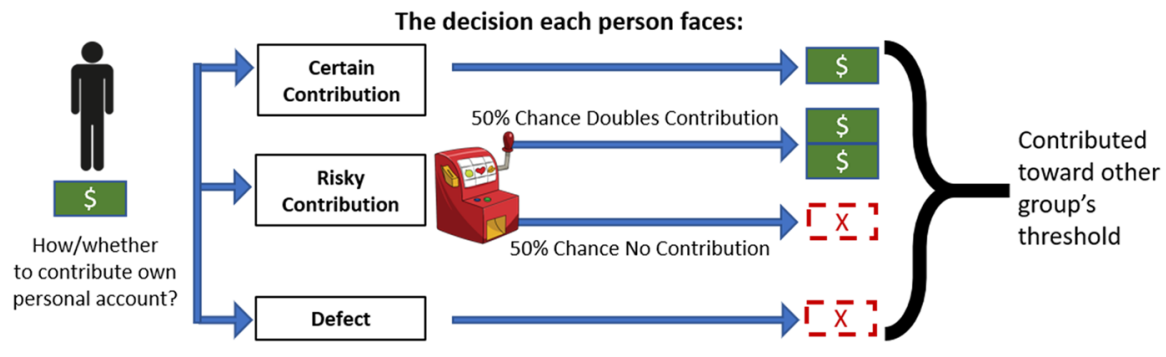

Fig. 3 Each player's contribution options

the threshold to be $60,80,100,120$, or 140 tokens. Notice that only at the two lowest thresholds can contributions even add up to the threshold (at best, 4 players $* 20$ tokens $=80$ ). This motivates our third change. Players have two ways to contribute: a direct or a risky contribution; see Fig. 3. A direct contribution simply gives 20 tokens to the beneficiary group. A risky contribution, however, has a $50 \%$ chance of being doubled to 40 tokens and a $50 \%$ chance of being lost entirely. With enough (successful) risky contributions, groups can meet the three highest thresholds.

To keep the game simple, most disaster games use, as ours will, a threshold known with certainty; however, players are also reasonably successful when the thresholds are uncertain (Barrett \& Dannenberg, 2012). Also, for simplicity players cannot realistically disagree about their understanding of the problem: In the game, it's clear that everyone will lose money if disaster is not averted and it's clear how everyone's actions affect the outcomes. For some real-world disasters (e.g., climate change), people disagree about whether there is a problem at all and whether their actions can make any difference.

Although we are interested in decision-making under complexity, if the problem is extraordinarily complex, solving it will be impossible. We sought a middle ground, which is why we selected a game involving thresholds and risky decisions. Humans and other animals are good at solving these kinds of problems with thresholds, at least when deciding individually and on their own behalf (e.g., Caraco et al., 1980; McDermott et al., 2008; Mishra et al., 2017; Rode et al., 1999). This ability shows up in politics (Arceneaux, 2012; McDermott et al., 2008; Osmundsen \& Petersen, 2019) and there is some evidence for it in group decisions (Andrews et al., 2018). Our unique contribution is to ask whether people can make these kinds of complex decisions well for others.

What should a player do who wants to help their beneficiary group? The game is designed such that any choice is reasonable but, depending on experimental condition, some choices are better than others (for full details, see the Game Theory Supplement). At all thresholds, a player could reasonably defect. If the rest of their group decides not to help, a given player should also defect-players cannot unilaterally prevent disaster. But if a player does contribute, then either type of contribution is reasonable (see Game Theory). However, with one exception, there is always a single, best set of choices. As shown in Table 1, at the two lowest thresholds no players need make risky contributions; at the three highest thresholds, some players 
Table 1 The most useful set of choices at each threshold

\begin{tabular}{lll}
\hline Threshold & Most useful sets of choices to help beneficiary group & $\begin{array}{c}\text { Average number of risky con- } \\
\text { tributions in most useful sets }\end{array}$ \\
\hline 60 & 3 Certain contributions and 1 defection & 0 \\
80 & 4 Certain contributions & 0 \\
100 & 3 Risky contributions and 1 certain contribution or & 2 \\
120 & 1 risky contribution and 3 certain contributions & 4 \\
140 & 4 Risky contributions & 3 \\
\hline
\end{tabular}

The most useful set of choices at each threshold. In game theory terms, these are the most efficient sets and represent payoff-dominant equilibria. For the 100 threshold, the minimum and maximum number of risky contributions in the best set are 1 and 3, respectively. Thus, the qualitative shape of the trend shown in the "Average Number" column would not change if the minima or maxima were substituted for the averages (for all other thresholds the minimum, maximum, and average are identical). See the supplemental information for full game theory model

must make risky contributions. Table 1 also predicts a slight drop in risky contributions at the highest threshold. Although players in past work are not robustly sensitive to this subtle prediction, they are robustly sensitive to the need to make more risky contributions at the highest thresholds (Andrews et al., 2018). To be clear, as is typical in game experiments, we do not expect real players to always make the best choices. Instead, we look for changes in average behavior across conditions (Samuelson, 2005). Thus, we expect more risky contributions at the highest thresholds-if players are in fact willing and able to help prevent disaster for others.

\section{Summary of Research Goals}

In sum, our basic question is whether people can make good decisions when preventing disaster for others. Theories in political science disagree about whether this is likely. We conducted three studies to find out. Empirically, we break the question into several pieces. First, we tested whether players would pay to prevent disaster for others. Although games like the dictator game reveal the basic fact that humans can be generous, it's unclear whether people working in groups to solve a complex, public goods problem for others will be generous. We used two benchmarks: the prediction of zero contributions for self-interested people and the behavior of players in previously published work playing similar games on their own behalf.

Second, we tested whether players would make useful choices for others. Doing so requires evaluating a complex task and selecting the appropriate type of contribution. Specifically, we tested whether players make fewer risky contributions at the lowest thresholds and more at the highest thresholds.

Third, we tested whether players would pay for information on how best to help. We cannot, of course, directly observe whatever cognitive costs our players pay to arrive at a decision. So, in Studies 2 and 3, we made this partly external by allowing players to buy advice from us. Whether people will pay to find and think about 
relevant information is a long-running question in political economy and political behavior (Downs, 1957). We can test whether real players want to buy advice; selfinterested agents should never do so. Moreover, we can test whether, after buying information, players make better decisions for others.

\section{Study 1: Disaster Decisions for Others}

With Study 1 we used the disaster game to test whether players working as a group would be willing and able to make costly, complex decisions to prevent disaster for others.

\section{Method}

\section{Participants}

We recruited 498 players through Amazon Mechanical Turk (MTurk), recruiting only U.S. citizens with a $98 \%$ HIT approval rate. At no point in the study was deception used. Our methods and informed consent process were approved by Stony Brook University's Human Subjects Institutional Review Board.

Players earned $50 \notin$ just for participating and could earn up to $100 \varnothing$ in bonus from gameplay. These stakes are typical of this setting (Amir et al., 2012). Experimental games tend to be played similarly despite large changes in the size of the stakes (Amir et al., 2012). Although MTurk players are not a representative sample of US citizens or voters, they are more diverse than typical student samples (Berinsky et al., 2012; Buhrmester et al., 2011). Gameplay is similar between MTurk and inperson laboratory samples (Horton et al., 2011). The disaster game in particular is played similarly by workers on MTurk for $\$ 1$ stakes and by students in the lab for \$20 stakes (Andrews et al., 2018; Del Ponte et al., 2017). (Our Study 3 uses a highstakes student sample.)

\section{The Disaster Game}

Players first read instructions and completed a series of comprehension questions (see the supplement). As with disaster games, we "framed" the game, describing the scenario as simulating climate change. After the instructions, players played a oneshot version of the disaster game: Each player simultaneously made a single decision and then the game ended. So, although we later matched players into groups to pay them, each player is statistically independent. Groups comprised four symmetric players. Each player had two pots of money (see below). Initially there was a $90 \%$ chance that disaster would destroy both pots. However, the group had a threshold, a monetary amount that if met would prevent the disaster (Fig. 1); thresholds were common knowledge. The threshold was randomly assigned between-subjects from $60 \phi, 80 \phi, 100 \phi, 120 \phi$, and 140ф. (For simplicity, when we describe all our 
experiments together, we refer to tokens. However, in the MTurk samples, gameplay was described directly in cents.)

Groups could not contribute to their own threshold, only to their beneficiary group's. If a group contributed enough to meet or exceed their beneficiary group's threshold, the beneficiary group kept any money they had remaining. Since all groups are identical, each player is simultaneously in a beneficiary group and giving to a beneficiary group. Groups were not reciprocally helping each other. For a given group, the group they could give to and the group they could receive from were independently and randomly determined (Fig. 2). Both the giving and receiving group had the same threshold. Of course, it's not always the case that disaster decision-making involves this type of symmetry. But in a large nation such as the US, different constituencies will face unique risks of disasters and, simultaneously, contribute to the disaster responses for other constituencies.

An important feature of our game is that each player started with two distinct pots of money. One pot, the "endowment," was worth $80 \phi$. Endowments were lost if disaster occurred but could not be spent to prevent disaster. They represent fixed property or infrastructure (like homes or roads) that can be damaged by disasters but cannot easily fund prevention.

The other pot, the "personal account," was worth 20ф. Players could choose whether and how to contribute their personal account to the beneficiary group (Fig. 3). Each player made this decision simultaneously and independently. This was an all or none decision: Players either contributed (spending all $20 \phi$ on the beneficiary group) or defected (keeping all 20ф). Players who chose to contribute had two options: (1) a certain contribution, giving $20 \phi$ directly to the beneficiary group's threshold, or (2) a risky contribution, which had a 50\% chance of doubling to $40 \phi$ and a $50 \%$ chance of being lost entirely. Both options had identical expected values. No matter what, contributed money disappeared.

\section{Predictions}

See the supplement for our game theory analysis. To summarize: First, self-interested players should never contribute to their beneficiary group; such players will strictly prefer to keep their money. Second, players with instrumental social preferences may contribute to the beneficiary group. Third, when players contribute to the beneficiary group, they should tend to make certain contributions at the lower thresholds and risky contributions at the higher thresholds. Whether players would be sensitive the predicted curvilinear trend in risky contributions (see Table 1), we viewed as an open question. 
Fig. 4 The percent of subjects making risky contributions, certain contributions and defecting in Study 1 (Internet sample, $\mathrm{n}=498$ ). Error bars are standard errors of the mean

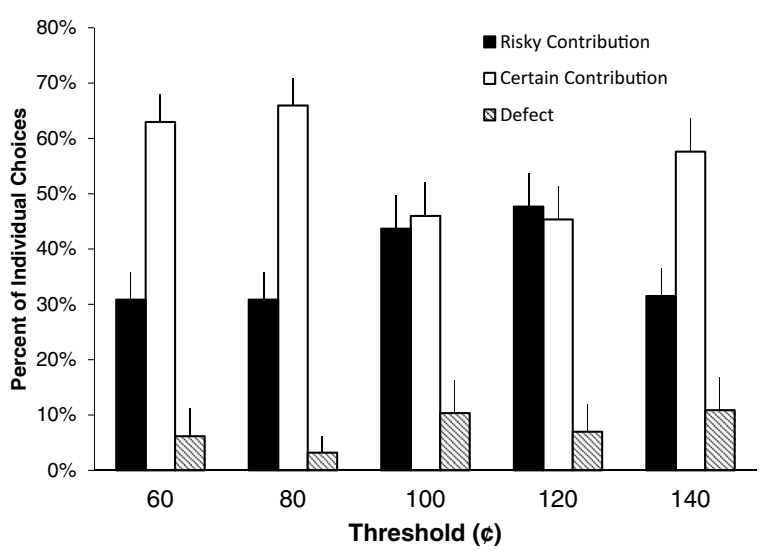

\section{Results}

To test our hypotheses, we examined our players' decisions about whether and how to contribute: the rates at which they defect, make certain contributions, and make risky contributions.

\section{Will Players Pay to Help Others?}

Although self-interested players should sacrifice nothing, the vast majority of our actual players, $82 \%$, sacrificed for their beneficiary group (compared to $0 \%$ : $t(497)=46.84, p<0.001$; all $p$-values two-tailed; Supplemental Figure 1). Previous work using the same game on the same population found that nearly the same number, 87\%, contributed on their own behalf (Andrews et al., 2018). As discussed in the game theory model, it's possible for a player with social preferences to not contribute. Taking contributions for oneself as the upper limit for the prevalence of social preferences, at most a small fraction, about $5 \%$ of our players, might have had unexpressed social preferences. We also find that the frequency of contributing in any form did not depend on the threshold (see Supplemental Table 1). 22\% of groups escaped disaster.

\section{Do Players Help in a Useful Way?}

We tested whether players made more risky investments at the three highest thresholds (potentially with a downtick at the highest; see Table 1). Do people make more risky investments in the top three thresholds compared to the bottom two? As shown in Fig. 4, they do $(t(496)=2.04, p=0.04)$.

Second, we tested for curvilinear effects using a linear probability regression model where the threshold was entered as a predictor twice, once as a linear term and once as squared term. Both terms are significant, suggesting that, as the 
threshold size increases, risky investments rise before falling again (Fig. 4 and Supplemental Table 2).

Third, as a robustness check we used an interrupted regression (Simonsohn 2018). Although squared terms are common, they may inflate Type II Errors by suggesting the trend fits a parabola when it merely flattens (Simonsohn 2018). We simultaneously estimated a linear model up to and including the $120 \phi$ threshold and a linear model including the $120 \phi-140 \phi$ thresholds; this is the breakpoint predicted by the game theory model. This analysis, too, finds that risky contributions rise over the first four thresholds $(p=0.09)$ and decline at the final threshold $(p=0.037$; Supplemental Figure 3).

As shown in Fig. 4, there is little systematic variation by threshold in defecting (see also Supplemental Table 1). Thus, changes in contributions by threshold are mainly due to substitutions between risky and certain contributions.

Overall, this experiment confirms the predictions of instrumental social preferences: Many players sacrificed and did so in a useful way. This occurred despite the experiment involving collective decision-making in a complex environment.

\section{Studies 2 and 3: Deciding for Others with the Opportunity to Buy Information}

Making useful decisions for others requires more than action. It requires information. People want to donate to charity in order to help others. But charities vary in their effectiveness and people must spend time and energy to learn whether a particular charity will make good use of their donations (Caviola et al., 2020). Will people engage in a costly information search when that information can only help others? Study 1 indirectly suggests they will, since players generally helped others.

But we can also examine costly information search by assessing whether players are willing to pay for advice on what to choose. Although not all players with social preferences will buy advice (some may trust their own judgment), the number who do puts a lower-bound on costly information search. Thus, in Studies 2 and 3, players first decided whether and how to help. Then, they could buy information and change their choice in response to what they learned. We made communicating the most useful choice straightforward by using only two thresholds, 80 and 120. In both, the most useful set of strategies involves all players making the same choice; all certain contributions at 80 and all risky contributions at 120 (Table 1). Study 2 used an internet sample with stakes of $\$ 1$. Study 3 used a student sample who played in our laboratory and who faced much larger stakes of $\$ 20$.

To check robustness, we divided Study 2 into two subsamples. The first, like Study 1 , had a $90 \%$ risk of disaster. The second subsample had only a $10 \%$ risk. (Study 3's entire sample had 90\% risk.) Perhaps in Study 1 the risk of disaster was so high players felt certain to lose their own money. If the money is definitely lost anyway, there is no practical difference between keeping it or helping others. In the $10 \%$ version, players are likely to keep their money even if disaster is not averted, which increases the expected cost of helping. If the results are similar in both subsamples, it would show the results are robust to this methods choice. 


\section{Method}

\section{Participants and Procedure}

For Study 2, 201 MTurk players completed the version with a starting 90\% risk of disaster and 208 players the version with $10 \%$ risk; other details were the same as Study 1. For Study 3, 213 undergraduate students completed the experiment in the laboratory at Stony Brook University's Center for Behavioral Political Economy. Students played through networked computers at semi-private stations. Like other labs for economic games, no studies run in our lab use deception and we did not use any here. Our methods and informed consent process for the lab version were also approved by the university's Human Subjects Institutional Review Board. Lab players completed the experiment in large sessions and did not know which other students were members of their own group or their beneficiary group. They received $\$ 7$ merely for participating. They were informed at the outset that the game would be played for tokens and that each token was worth $20 \notin ; 100$ bonus tokens were at stake, or $\$ 20$.

Studies 2 and 3 were identical to Study 1 with the following exceptions. After players made their initial choice of how and whether to contribute to the beneficiary group, they could pay 1 token to learn what choice would most help the beneficiary group. If they paid, they were allowed to make a new choice based on what they learned. In Study 2, if they paid for information, we assumed they wanted to contribute and only allowed them to choose between certain and risky contributions. In Study 3, we relaxed this and allowed players who bought information to defect after buying information.

We recognize that 1 token is a small amount. We assume there is some point at which few players will purchase information (say, if it cost their entire endowment). Our goal is not to find such a price point. Instead, we sought to test whether players will ever pay for information. Using a low price allows us to set an upper-bound on information purchasing. It also provides a critical test of theories that predict zero willingness to buy information.

\section{Predictions}

Self-interested players should neither contribute nor purchase information. Players with social preferences, however, might buy information if unsure how best to help. Because the price is small, it does not change the larger game dynamics by much.

\section{Analysis Strategy}

In Study 1, risky contributions differed between the 80- and 120-token thresholds by 14 percentage-points. In five studies where people played for themselves, the same differences were 3, 9, 9, 10, and 14 percentage-points, averaging nine points (Andrews et al., 2018). Thus, Study 1 is on the high end and we would not expect Studies 2 and 3 to have such large effects. To maximize power when we test for 
Fig. 5 The percent of subjects making risky contributions in Study 2 (two Internet samples, total $\mathrm{n}=409$ ) and Study 3 (student sample, $\mathrm{n}=213)$. Error bars are standard errors of the mean

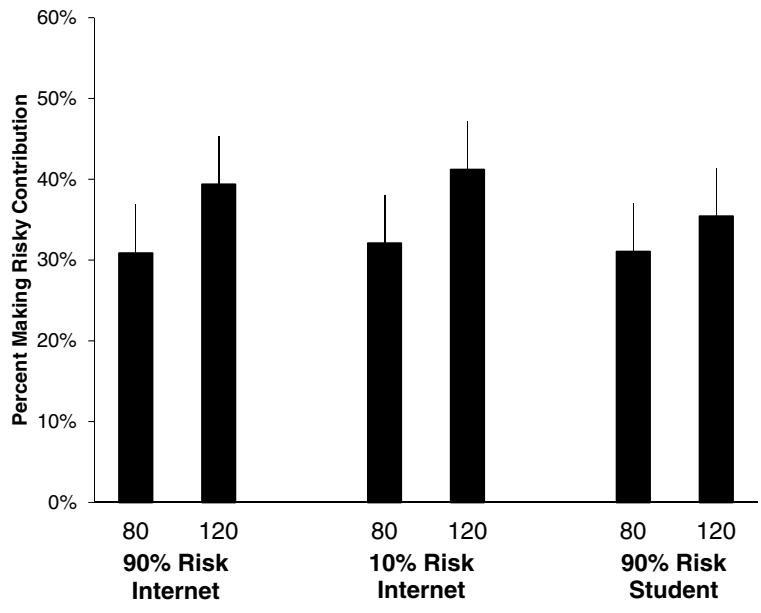

differences by thresholds, we pool all the samples for a $t$-test (in the supplement we show the effect does not vary by subsample). Remember that our main goal with Studies 2 and 3 is to study purchasing information, which required using 80-token and 120-token thresholds for straightforward communication. If our goal was replicating Study 1 with just two thresholds, 60-token and 100-token thresholds would be the better choice; these showed the largest pairwise differences in past work.

\section{Results}

We again analyzed the rates at which players defected, made certain contributions, and made risky contributions. We also analyzed whether players bought information on how best to help and how they changed their contribution in response to this information.

\section{Will Players Pay to Help Others?}

Replicating Study 1, the overwhelming majority of players sacrificed for their beneficiary group, averaging $87 \%$ contributing in some fashion before players were given the option to buy information (87\% Study 2-90\% Risk; 87\% Study $2-10 \%$ Risk; $86 \%$ Study 3; compared to $0 \%$, all $t \mathrm{~s}>35, p \mathrm{~s}<0.0001$ ). This is identical to the $87 \%$ contributing found in past work on people deciding on their own behalf and of course is much larger than the $0 \%$ expected from self-interested players. However, only $12 \%$ of groups had their thresholds met (the comparable percentage for these thresholds in Study 1 was 30\%). 
Fig. 6 The percent of players buying information based on whether they initially made a risky, certain, or no contribution in Study 2 (Internet samples) and Study 3 (student sample). Error bars are standard errors of the mean

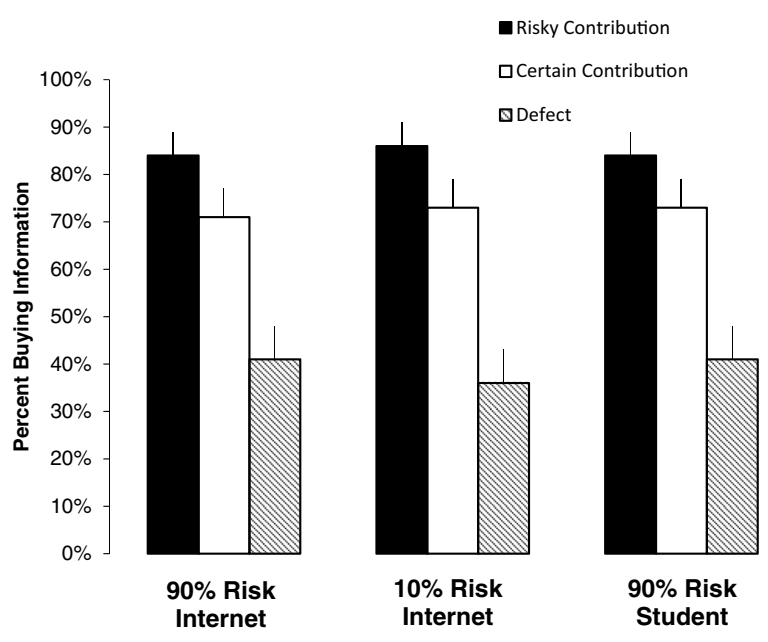

\section{Do Players Help in a Useful Way?}

That is, are there more risky contributions at 120 compared to 80 ? Pooling all three samples (see Analysis Strategy above), people do make more risky contributions at the higher threshold (Fig. $5 ; t(620)=1.96, p=0.05$; see also Supplemental Figure 2) and the effect does not vary between samples (Supplemental Table 3). On average, the difference in Studies 2 and 3 is 7 percentage-points. (These data are for decisions made before players were given the option to buy information.) Including Study 1, the average difference is 9 percentage-points, identical to the average when players decided for themselves in prior work (see Analysis Strategy).

\section{Will Players Pay to Learn How Best to Help?}

Self-interested players should not. In contrast to this expectation, $72 \%$ of players bought information. Figure 6 shows who bought information based on their initial contribution decision and their sample. Not surprisingly, players already willing to contribute were more likely to buy information than players who defected (testing each sample separately, $t \mathrm{~s}>3.5, \mathrm{ps}<0.001$ ). For instance, in Study $3,77 \%$ of players who helped also bought information, whereas only $40 \%$ of defectors did. Among players initially willing to contribute, risky contributors were more likely to buy information than certain contributors (all $t \mathrm{~s}>2.5, p \mathrm{~s}<0.005$ ). For instance, in Study 3 , this difference is $84 \%$ versus $73 \%$ of such players buying information. 
Fig. 7 The percent of players in the entire sample making the useful choice before and after they have the opportunity to buy information at each threshold. The most useful choice at the 80 threshold is to make a certain contribution, and the most useful choice at the 120 threshold is to make a risky contribution. Error bars are standard errors of the mean

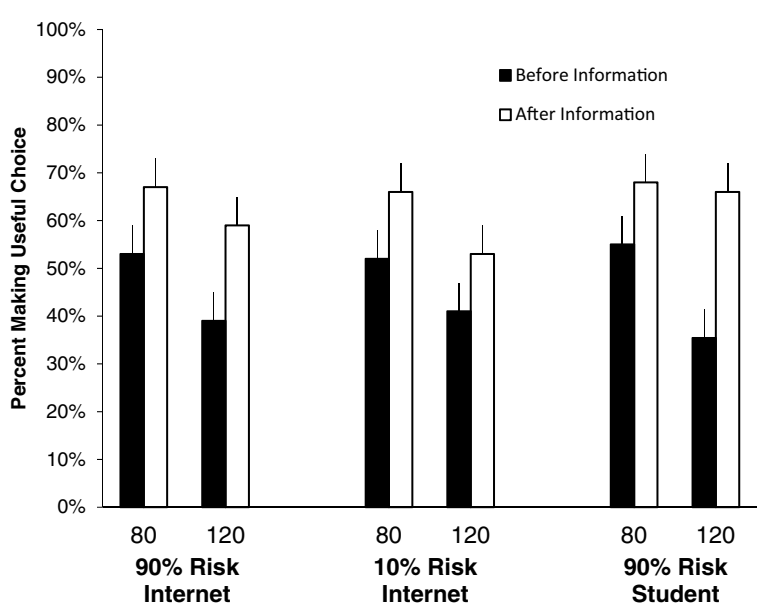

\section{Did Buying Information Make Decisions More Useful?}

Yes: Looking at players initially willing to contribute who bought information and were not initially making the most useful choice, on average $56 \%$ switched to the most useful choice (53\%, Study 2-90\% Risk; 51\%, Study 2-10\% Risk; 63\%, Study 3 ). Although this was a majority of such players, it was not an overwhelming majority. Perhaps some players were motivated to be consistent or, despite our apparent expertise, believed their original decision was best. Nonetheless, many players wanted this costly information and a majority of them did switch their contribution decisions after buying this information. Notably, a much smaller percentage of players who bought information and initially did make the most useful choice then switched to a less useful choice, $10 \%$ on average $(9 \%, 13 \%$, and $7 \%$, respectively).

Next, we tested whether the opportunity to buy information increased the aggregate number of people making the most useful choice. In these before-and-after comparisons, people who did not purchase information could not change their response; thus, their before and after choices were necessarily the same. As shown in Fig. 7, for both thresholds the samples were more likely to make useful contributions after the opportunity to buy information (80-token thresholds: Wilcox signed-rank test $z \mathrm{~s}>3$, $p s<0.002 ; 120$-token threshold: Wilcox signed-rank test $z \mathrm{~s}>2, p \mathrm{~s}<0.05$ ).

\section{Did Players Understand the Game?}

Our goal was to create a reasonably complex decision-making environment. Could a failure to understand the game somehow have led to the results we observe? It's not clear how error could lead to the predicted pattern of risky contributions. Nonetheless, we provide extensive tests in the Supplemental Results that show for all three 
studies that players' useful decision making is not due to this alternative explanation. We included a series of comprehension checks to test players' understanding and test if that predicted how they played the game (based on Berinsky et al., 2012). We find that whether players contributed in any form is generally unrelated to passing the comprehension questions. We also find that, if anything, decisions are more likely to be useful when made by players who initially understood the game better. The Supplemental Information also analyzes two additional subsamples collected with Study 2 that allow us to further test whether players understand the game; these supplemental results also suggest players did in fact understand it. Our results are not driven by misunderstanding.

\section{Discussion}

Can people make useful political decisions about disasters? When reasoning about disasters and politics alike, some researches argue people will not make useful decisions even when deciding for themselves (Downs, 1957). Indeed, people are often uninformed about politics (Delli Carpini \& Keeter, 1993). However, there is evidence suggesting people can make effective decisions to prepare for oncoming disasters, even when how best to do so isn't straightforward (Lindell $\&$ Perry, 2012). For example, people are sensitive to the details of disasters, and are more likely to evacuate in the face of more extreme events (Dash \& Gladwin, 2007; Mileti \& Fitzpatrick, 1992; Sorensen, 2000). Further, people can use information from trusted sources about oncoming disasters and how to best respond (Lindell \& Perry, 2012).

We extend this work by asking whether citizens can, in principle, make useful disaster decisions for others. People are often asked to do so, for example when they decide whether to wear a mask during a pandemic (Zhang et al., 2020) or not to evacuate until those most at risk are able to do so (Stein et al., 2014). In a game simulating a complex disaster that was a public good, we showed that players were willing to spend money for others and did so in useful ways. Moreover, many purchased information about how to help, which then improved their decisions. This is consistent with theories of instrumental social preferences. Our novel contribution is to show that people help and do so usefully even in a complex decision-making environment where every choice is potentially reasonable. Our findings are inconsistent with theories of pure self-interest, which predict no helping. Although some of our players might have helped for non-instrumental reasons (e.g., the warm glow of helping), such preferences cannot be whole story given that players' decisions changed in useful ways across conditions. Finally, our results are also inconsistent with the view that people are generally are irrational in the political arena, which would have predicted random helping.

Of course, real-world disaster politics are more complicated than our strippeddown game. The institutions and rules of play in our game were purposefully transparent to players, while real-world institutions are often anything but. Our game has an objective, most socially useful option that can be identified using basic game theory. Previous work has shown that people are good at identifying 
this option on their own behalf (Andrews et al., 2018). While in our game players could buy information from experts, they could often make the best decision without help. In the real world, citizens depend on elites for political cues (Zaller, 1992) and information about how to respond to disasters (Lindell \& Perry, 2012). Moreover, in our game, the interest of the beneficiary group is clear-to avoid disaster. In many real-world situations, what is in the best interests of others is often debatable and may raise concerns about paternalism (Thaler \& Sunstein, 2009); our game avoids this. Overall, coming to a useful answer was easier in our game than in real environments.

Further, in our game players received straightforward advice from a single, unbiased source. In the real world, the best approach is nearly always debatable and contested, with multiple experts and media sources providing sharply conflicting advice. When citizens receive conflicting advice, they may reduce their political participation (Matsusaka, 1995). Information overload also allows people to focus on what is consistent with their preexisting opinions (Dilliplane, 2011) or to ignore information entirely (Prior, 2005). Political elites are also incentivized to exaggerate or misrepresent information in their favor (Miller \& Hammond, 1994). Indeed, while our game was designed to tap into a heuristic, not all political problems can be easily solved with heuristics (Lau \& Redlawsk, 2001).

In sum, our experiments show that citizens might be willing to make useful decisions for others. Our players paid to help and did so in useful ways. Further, they sought out costly information to improve their helping. Nonetheless, more research is needed to understand how this can scale up to more complex political and economic decision-making problems, including through the vote.

Supplementary Information The online version contains supplementary material available at https://doi. org/10.1007/s11109-021-09700-2.

Acknowledgements We would like to thank the research assistants who helped facilitate the lab experiment: Daniella Alva, Donovan Bush, Narmin Butt, Pei-Hsun Hsieh, Hana Kim, and Elias Shammas. A previous version of this paper was presented at the annual conference of the American Political Science Association in 2019.

Author Contributions All authors contributed equally to this manuscript.

Funding Funding was provided by the Center for Behavioral Political Economy at Stony Brook University.

Data Availability All data and materials are available at: https://dataverse.harvard.edu/dataset.xhtml?persi stentId=doi:10.7910/DVN/YCOSD2.

\section{Declarations}

Conflict of interest The authors declare no conflicts of interest. 


\section{References}

Amir, O., Rand, D. G., \& Gal, Y. K. (2012). Economic games on the internet: The effect of \$1 stakes. PLOS ONE. https://doi.org/10.1371/journal.pone.0031461

Andreoni, J. (1995). Warm-glow versus cold-prickle: The effects of positive and negative framing on cooperation in experiments. The Quarterly Journal of Economics, 110(1), 1-21. https://doi.org/10. $2307 / 2118508$

Andrews, T. M., Delton, A. W., \& Kline, R. (2018). High-risk high-reward investments to mitigate climate change. Nature Climate Change, 8, 890-894. https://doi.org/10.1038/s41558-018-0266-y

Arceneaux, K. (2012). Cognitive biases and the strength of political arguments. American Journal of Political Science, 56(2), 271-285. https://doi.org/10.1111/j.1540-5907.2011.00573.x

Barrett, S., \& Dannenberg, A. (2012). Climate negotiations under scientific uncertainty. Proceedings of the National Academy of Sciences of the United States of America, 109(43), 17372-17376. https:// doi.org/10.1073/pnas.1208417109

Barrett, S., \& Dannenberg, A. (2014). Sensitivity of collective action to uncertainty about climate tipping points. Nature Climate Change, 4(1), 36-39. https://doi.org/10.1038/nclimate2059

Berinsky, A. J., Huber, G. A., \& Lenz, G. S. (2012). Evaluating online labor markets for experimental research: Amazon.com's mechanical Turk. Political Analysis, 20(03), 351-368. https://doi.org/10. 1093/pan/mpr057

Bernauer, T., \& McGrath, L. F. (2016). Simple reframing unlikely to boost public support for climate policy. Nature Climate Change, 6(7), 680-683. https://doi.org/10.1038/nclimate2948

Bolsen, T., Ferraro, P. J., \& Miranda, J. J. (2014). Are voters more likely to contribute to other public goods? Evidence from a large-scale randomized policy experiment. American Journal of Political Science, 58(1), 17-30. https://doi.org/10.1111/ajps.12052

Bornstein, G., \& Yaniv, I. (1998). Individual and group behavior in the ultimatum game: Are groups more "rational" players? Experimental Economics, 1(1), 101-108. https://doi.org/10.1023/A:10099 14001822

Buhrmester, M., Kwang, T., \& Gosling, S. D. (2011). Amazon's mechanical turk: A new source of inexpensive, yet high-quality, data? Perspectives on Psychological Science. https://doi.org/10.2307/ 41613414

Bynum, A., Kline, R., \& Smirnov, O. (2016). Passive non-participation versus strategic defection in a collective risk social dilemma. Journal of Theoretical Politics, 28(1), 138-158. https://doi.org/10.1177/ 0951629815586880

Camerer, C. F. (2011). Behavioral game theory: Experiments in strategic interaction. Princeton University Press.

Campbell, A., Converse, P. E., Miller, W. E., \& Stokes, D. (1980). The American voter. University of Chicago Press.

Caraco, T., Martindale, S., \& Whittam, T. S. (1980). An empirical demonstration of risk-sensitive foraging preferences. Animal Behaviour, 28(3), 820-830. https://doi.org/10.1016/S0003-3472(80) 80142-4

Cason, T. N., \& Mui, V. (1997). A laboratory study of group polarisation in the team dictator game. The Economic Journal, 107(444), 1465-1483. https://doi.org/10.1111/j.1468-0297.1997.tb00058.x

Caviola, L., Schubert, S., \& Nemirow, J. (2020). The many obstacles to effective giving. Judgement and Decision Making. https://doi.org/10.31234/osf.io/3z7hj

Charness, G., \& Rabin, M. (2002). Understanding social preferences with simple tests. The Quarterly Journal of Economics, 117(3), 817-869. https://doi.org/10.1162/003355302760193904

Chen, J. (2013). Voter partisanship and the effect of distributive spending on political participation. American Journal of Political Science, 57(1), 200-217. https://doi.org/10.1111/j.1540-5907.2012. 00613.x

Converse, P. E. (1964). The nature of belief systems in mass publics. Critical Review, 18(1-3), 1-74. https://doi.org/10.1080/08913810608443650

Dannenberg, A., Löschel, A., Paolacci, G., Reif, C., \& Tavoni, A. (2015). On the provision of public goods with probabilistic and ambiguous thresholds. Environmental and Resource Economics, 61(3), 365-383. https://doi.org/10.1007/s10640-014-9796-6

Dash, N., \& Gladwin, H. (2007). Evacuation decision making and behavioral responses: Individual and household. Natural Hazards Review, 8(3), 69-77. https://doi.org/10.1061/(asce)1527-6988(2007)8: $3(69)$ 
Dawes, C. T., Loewen, P. J., \& Fowler, J. H. (2015). Social preferences and political participation. The Journal of Politics, 73(3), 845-856. https://doi.org/10.1017/S0022381611000508

Del Ponte, A., Delton, A. W., Kline, R., \& Seltzer, N. A. (2017). Passing it along: Experiments on creating the negative externalities of climate change. The Journal of Politics, 79(4), 1444-1448. https:// doi.org/10.1086/692472

Del Ponte, A., Delton, A. W., \& DeScioli, P. (2021). Altruism and spite in politics: How the mind makes welfare tradeoffs about political parties. Political Behavior, 1, 1-22.

Delli Carpini, M. X., \& Keeter, S. (1993). Measuring political knowledge: Putting first things first. American Journal of Political Science, 37(4), 1179. https://doi.org/10.2307/2111549

Delton, A. W., DeScioli, P., \& Ryan, T. J. (2020). Moral obstinacy in political negotiations. Political Psychology, 41(1), 3-20. https://doi.org/10.1111/pops.12612

DeScioli, P., \& Krishna, S. (2013). Giving to whom? Altruism in different types of relationships. Journal of Economic Psychology, 34, 218-228. https://doi.org/10.1016/J.JOEP.2012.10.003

Dilliplane, S. (2011). All the news you want to hear: The impact of partisan news exposure on political participation. Public Opinion Quarterly, 75(2), 287-316. https://doi.org/10.1093/poq/nfr006

Downs, A. (1957). An economic theory of political action in a democracy. Journal of Political Economy, 65(2), 135-150. https://doi.org/10.1086/257897

Drabek, T. E. (1983). Shall we leave? A study on family reactions when disaster strikes. Emergency Management Review, 1, 25-29.

Dreber, A., \& Nowak, M. A. (2008). Gambling for global goods. Proceedings of the National Academy of Sciences of the United States of America, 105(7), 2261-2262. https://doi.org/10.1073/ pnas.0800033105

Edlin, A., Gelman, A., \& Kaplan, N. (2007). Voting as a rational choice. Rationality and Society, 19(3), 293-314. https://doi.org/10.1177/1043463107077384

Feddersen, T., Gailmard, S., \& Sanfroni, A. (2009). Moral bias in large elections: Theory and experimental evidence. American Political Science Review, 103(2), 175-192.

FEMA. (2004). Are you ready? An in-depth guide to citizen preparadness. http://www.fema.gov/pdf/ areyouready/areyouready_full.pdf. Accessed 15 Dec 2020

Fowler, J. H. (2006). Altruism and turnout. The Journal of Politics, 68(3), 674-683. https://doi.org/ 10.1111/j.1468-2508.2006.00453.x

Fowler, J. H., \& Kam, C. D. (2007). Beyond the self: Social identity, altruism, and political participation. The Journal of Politics. https://doi.org/10.1111/J.1468-2508.2007.00577.X

Gilens, M., \& Thal, A. (2018). Doing well and doing good? Public Opinion Quarterly, 82(2), 209230. https://doi.org/10.1093/poq/nfy020

Hamlin, A., \& Jennings, C. (2011). Expressive political behaviour: Foundations, scope and implications. British Journal of Political Science, 41(03), 645-670. https://doi.org/10.1017/S000712341 1000020

Heersink, B., Jenkins, J. A., Olson, M. P., \& Peterson, B. D. (2020). Natural disasters, 'partisan retrospection', and U.S. presidential elections. Political Behavior. https://doi.org/10.1007/ s11109-020-09653-y

Heersink, B., Peterson, B. D., \& Jenkins, J. A. (2017). Disasters and elections: Estimating the net effect of damage and relief in historical perspective. Political Analysis, 25(2), 260-268. https:// doi.org/10.1017/pan.2017.7

Henrich, J., Boyd, R., Bowles, S., Camerer, C., Fehr, E., Gintis, H., et al. (2005). "Economic man" in cross-cultural perspective: Behavioral experiments in 15 small-scale societies. Behavioral and Brain Sciences, 28(06), 795-815. https://doi.org/10.1017/S0140525X05000142

Horton, J. J., Rand, D. G., \& Zeckhauser, R. J. (2011). The online laboratory: Conducting experiments in a real labor market. Experimental Economics, 14(3), 399-425. https://doi.org/10.1007/ s10683-011-9273-9

IPCC. (2014). Climate change 2014: Impacts, adaptation, and vulnerability. Contributions of working group II to the fifth assessment report on the intergovernmental panel on climate change. In: R. Pachouri, L. Meyer (Eds.) Geneva, Switzerland.

Jacquet, J., Hagel, K., Hauert, C., Marotzke, J., Röhl, T., \& Milinski, M. (2013). Intra-and intergenerational discounting in the climate game. Nature Climate Change, 3(12), 1025.

Jordan, M. R., Jordan, J. J., \& Rand, D. G. (2017). No unique effect of intergroup competition on cooperation: Non-competitive thresholds are as effective as competitions between groups for increasing human cooperative behavior. Evolution and Human Behavior, 38(1), 102-108. https:// doi.org/10.1016/j.evolhumbehav.2016.07.005 
Kim, Y. C., \& Kang, J. (2010). Communication, neighbourhood belonging and household hurricane preparedness. Disasters, 34(2), 470-488.

Kinder, D. R., \& Kiewiet, D. R. (1981). Sociotropic politics: The American case. British Journal of Political Science, 11(2), 129-161. https://doi.org/10.1017/S0007123400002544

Kuklinski, J. H., \& Quirk, P. J. (2000). Reconsidering the rational public: Cognition, heuristics, and mass opinion. In A. Lupia, M. D. McCubbins, \& S. L. Popkin (Eds.), Elements of reason: Cognition, choice, and the bounds of rationality (pp. 951-971). Cambridge University Press.

Lau, R. R., \& Redlawsk, D. P. (2001). Advantages and disadvantages of cognitive heuristics in political decision making. American Journal of Political Science, 45(4), 951. https://doi.org/10.2307/ 2669334

Lindell, M. K., \& Perry, R. W. (2012). The protective action decision model: Theoretical modifications and additional evidence. Risk Analysis, 32(4), 616-632. https://doi.org/10.1111/j.15396924.2011.01647.x

Malhotra, N., \& Kuo, A. G. (2008). Attributing blame: The public's response to Hurricane Katrina. Journal of Politics, 70(1), 120-135. https://doi.org/10.1017/S0022381607080097

Matsusaka, J. G. (1995). Explaining voter turnout patterns: An information theory. Public Choice, 84(1-2), 91-117. https://doi.org/10.1007/BF01047803

McDermott, R., Fowler, J. H., \& Smirnov, O. (2008). On the evolutionary origin of prospect theory preferences. Journal of Politics, 70(2), 335-350. https://doi.org/10.1017/S0022381608080341

Mileti, D. S., \& Fitzpatrick, C. (1992). The causal sequence of risk communication in the parkfield earthquake prediction experiment. Risk Analysis, 12(3), 393-400. https://doi.org/10.1111/j.15396924.1992.tb00691.x

Mileti, D. S., \& Sorensen, J. H. (1987). Why people take precautions against natural disasters. Cambridge University Press.

Milinski, M., Hilbe, C., Semmann, D., Sommerfeld, R., \& Marotzke, J. (2016). Humans choose representatives who enforce cooperation in social dilemmas through extortion. Nature Communications, 7, 10915. https://doi.org/10.1038/ncomms10915

Milinski, M., Sommerfeld, R. D., Krambeck, H. J., Reed, F. A., \& Marotzke, J. (2008). The collective-risk social dilemma and the prevention of simulated dangerous climate change. Proceedings of the National Academy of Sciences of the United States of America, 105(7), 2291-2294. https:// doi.org/10.1073/pnas.0709546105

Miller, G., \& Hammond, T. (1994). Why politics is more fundamental than economics. Journal of Theoretical Politics, 6(1), 5-26. https://doi.org/10.1177/0951692894006001001

Mishra, S., Barclay, P., \& Sparks, A. (2017). The relative state model: Integrating need-based and ability-based pathways to risk-taking. Personality and Social Psychology Review, 21(2), 176198. https://doi.org/10.1177/1088868316644094

Morton, R. B., \& Williams, K. C. (2010). Experimental political science and the study of causality: From nature to the lab. Cambridge University Press.

Myers, T. A., Maibach, E. W., Roser-Renouf, C., Akerlof, K., \& Leiserowitz, A. (2013). The relationship between personal experience and belief in the reality of global warming. Nature Climate Change, 3(4), 343-347. https://doi.org/10.1038/nclimate1754

Osmundsen, M., \& Petersen, M. B. (2019). Framing political risks: Individual differences and loss aversion in personal and political situations. Political Psychology. https://doi.org/10.1111/pops. 12587

Paton, D. (2003). Disaster preparedness: A social-cognitive perspective. Disaster Prevention and Management: An International Journal, 12(3), 210-216. https://doi.org/10.1108/0965356031 0480686

Prior, M. (2005). News vs. entertainment: how increasing media choice widens gaps in political knowledge and turnout. American Journal of Political Science, 49(3), 577-592. https://doi.org/ 10.1111/j.1540-5907.2005.00143.x

Rode, C., Cosmides, L., Hell, W., \& Tooby, J. (1999). When and why do people avoid unknown probabilities in decisions under uncertainty? Testing some predictions from optimal foraging theory. Cognition, 72(3), 269-304. https://doi.org/10.1016/S0010-0277(99)00041-4

Samuelson, L. (2005). Economic theory and experimental economics. Journal of Economic Literature, 43(1), 65-107. https://doi.org/10.1257/0022051053737816

Simonsohn, U. (2018). Two lines: A valid alternative to the invalid testing of U-shaped relationships with quadratic regressions. Advances in Methods and Practices in Psychological Science, 1(4), 538-555. https://doi.org/10.1177/2515245918805755. 
Sorensen, J. H. (2000). Hazard warning systems: Review of 20 years of progress. Natural Hazards Review, 1(2), 119-125. https://doi.org/10.1061/(asce)1527-6988(2000)1:2(119)

Sousa-Pinto, B., Fonte, A. P., Lopes, A. A., Oliveira, B., Fonseca, J. A., Costa-Pereira, A., \& Correia, O. (2020). Face masks for community use: An awareness call to the differences in materials. Respirology. https://doi.org/10.1111/resp.13891

Stein, R., Buzcu-Guven, B., Dueñas-Osorio, L., \& Subramanian, D. (2014). The private and social benefits of preparing for natural disasters. International Journal of Mass Emergencies and Disasters, 32(3), 459-483.

Sunjaya, A. P., \& Jenkins, C. (2020). Rationale for universal face masks in public against COVID-19. Respirology. https://doi.org/10.1111/resp.13834

Tavoni, A., Dannenberg, A., Kallis, G., \& Löschel, A. (2011). Inequality, communication, and the avoidance of disastrous climate change in a public goods game. Proceedings of the National Academy of Sciences of the United States of America, 108(29), 11825-11829. https://doi.org/10. 1073/pnas.1102493108

Thaler, R. H., \& Sunstein, C. R. (2009). Nudge: Improving decisions about health, wealth, and happiness. Penguin.

Van Der Pligt, J. (1998). Perceived risk and vulnerability as predictors of precautionary behaviour. British Journal of Health Psychology. https://doi.org/10.1111/j.2044-8287.1998.tb00551.x

Wilson, R. K. (2011). The contribution of behavioral economics to political science. Annual Review of Political Science, 14(1), 201-223. https://doi.org/10.1146/annurev-polisci-041309-114513

Woon, J. (2012). Laboratory tests of formal theory and behavioral inference. Experimental political science (pp. 54-71). Palgrave Macmillan.

Zaller, J. (1992). The nature and origins of mass opinion. Cambridge University Press.

Zhang, R., Li, Y., Zhang, A. L., Wang, Y., \& Molina, M. J. (2020). Identifying airborne transmission as the dominant route for the spread of COVID-19. Proceedings of the National Academy of Sciences of the United States of America, 117(26), 14857-14863. https://doi.org/10.1073/pnas.2009637117

Publisher's Note Springer Nature remains neutral with regard to jurisdictional claims in published maps and institutional affiliations. 